\title{
Yacimientos Chatelperronienses en el Norte de España
}

\author{
Pablo J. Morales Grajera
}

\section{RESUMEN ABSTRACT}

El Chatelperroniense, esta representado en el Norte de España por los yacimientos de Cueva Morín y El Pendo (Cantabria) y Labeko Koba (Guipúzcoa), pero a partir del año 1987 se han realizado excavaciones en la Cova Da Valiña (Lugo), que parecen adscribir el nivel 1 de dicho yacimiento al Perigordiense Inferior.

El presente artículo es una sintesis de los trabajos de investigación llevados a cabo en estos tres yacimientos, sobre este periodo de transición entre el Paleolítico Medio y el Superior.

\author{
PALABRAS CLAVE \\ Perigordiense Inferior, \\ Chatelperroniense, cuchillo de \\ Chatelperron, Paleolítico.
}

Chatelperronian is representated in the North of Spain by three sites: Cueva Morín and El Pendo (Cantabria) and Labeko Koba (Guipúzcoa). It's after 1987 when Cova Da Valiña (Lugo) was excavated, and its Level 1 was correlated with Chatelperronian horizon. This work is a summary of all research works realized in three site about transition period between Middle and Upper Paleolithic.

KEY WORDS

Early Perigordian, Chatelperronian, Chatelperron knife, Paleolithic

\section{INTRODUCCIÓN}

En esta sintesis haremos un recorrido por los diferentes yacimientos, ubicados en el norte de nuestro país, en los que se ha detectado este período cultural y comentaremos brevemente estos enclaves arqueológicos. 
Este período de transición entre el Paleolítico Medio y el Superior es el que, en la división del Auriñaciense llevada a cabo por $\mathrm{H}$. Breuil en 1912, corresponde al Auriñaciense Inferior, que presenta puntas de dorso curvo 0 cuchillos de Chatelperron. Más tarde, en los años 30, D. Peyrony divide esta secuencia en dos ramas que evolucionan paralelamente, el Perigordiense y el Auriñaciense. Para D. Peyrony el Perigordiense está subdividido en tres fases, correspondiendo la primera, Perigordiense Inferior, con el Chatelperroniense o Perigordiense I. En 1946 este autor divide finalmente el Perigordiense en dos grupos distintos: Chatelperroniense y Dufour.

En la actualidad, este período es considerado como parte del Paleolítico Superior Inicial. Las excavaciones llevadas a cabo en el último cuarto de siglo han posibilitado la subdivisión del período, llevada a cabo por H. Delporte:

- Musteriense pre-chatelperroniense. Presenta una industria musteriense evolucionada con prototipos de formas del Paleolítico Superior.

- Chatelperroniense I o de tradición musteriense. Esta fase es una mezcla de industrias de tradición Musteriense y de industrias del Paleolítico Superior.

- Chatelperroniense II o típico. Es el que corresponde a la definición de Chatelperroniense. Difiere de la etapa anterior por la desaparición de las formas musterienses.

- Chatelperroniense III. En él coexisten formas del Chatelperroniense II y del Auriñaciense.

- Chatelperroniense IV. Es una forma evolucionada del Chatelperroniense II con influencias del Chatelperroniense III.

- Chatelperroniense V o pregravetiense. Esta fase se corresponde con el Perigordiense III de D. Peyrony. Es el punto final de la evolución del Chatelperroniense. (Delporte, H., 1956).

Pero es a partir de 1958 cuando F. Bordes (1968) propone una evolución del Chatelperroniense a partir de un Musteriense de Tradición Achelense Tipo B con piezas del tipo Abrí Audí, lo cual es válido para la secuencia francesa. Años más tarde G. Laplace (1962) propone la formación de un sintetotipo "auriñaco-perigordiense" a partir de un Musteriense de Denticulados; esta teoría actualmente no goza de gran popularidad, pero en la Región Cantábrica el Chatelperroniense se superpone a un Musteriense de Denticulados. 
PERIGORDIENSE INFERIOR O CHATELPERRONIENSE.

\section{GENERALIDADES}

Las primeras industrias en las que aparecen los rasgos del Paleolítico Superior son, como hemos dichos más arriba, el Perigordiense Inferior o Chatelperroniense y el Auriñaciense, que aparecen en Europa Occidental durante el interestadial Hengelo (Würm II/III).

La cronología del Perigordiense Inferior oscila entre el 36.000-30.000 B.P., siendo durante un tiempo contemporáneo del Auriñaciense. Las fechas que tenemos de los yacimientos franceses oscilan mucho, siendo la datación más antigua la del nivel IX de Renne-Arcy (OxA 3465) con 45.100 \pm 2.800 (HEDGES, et alii, 19 ), dándose también en este yacimiento dataciones que oscilan alrededor de los 33.000 , siendo la fecha más moderna del yacimiento la que ofrece el nivel $10(L 340 \mathrm{D})$ con $15.350 \pm 400$ (DELIBRIAS, G. Y EVIN, J., 1974); pero otros yacimientos de Francia ofrecen dataciones más modernas que las de Renne-Arcy, como es el caso de La Grande Roche que, en su nivel E.Noir, nos ofrece fechas de $20.300 \pm 500$ (Lv 791) y de $11.910 \pm 200$ (Lv 790) (DELIBRIAS, G. Y EVIN, J., 1980). En cuanto a los yacimientos españoles, las únicas fechas de que disponemos provienen de Cueva Morín, en la que el nivel 10 nos ofrece dos fechas, una de $35.873 \pm 6.580$ (SI-51-A) y otra de $27.776 \pm 951$ (SI-951) (GONZALEZ ECHEGARAY, J. Y FREEMAN, L.G., 1971); Labeko Koba que nos ofrece tres fechas distintas para el nivel IX: nivel IX base $26.575 \pm$ 505 (Ua-3034), nivel IX centro $29.750 \pm 740$ (Ua-3325)y por último el nivel IX base $34.215 \pm 1265$ (Ua-3324) (ARRIZABALAGA VALBUENA, A., 1995); la última fecha que tenemos para este período en la Península la proporciona Cova Da Valiña, con una fecha de $34.800+1.900 /-1.500$ (GrN 17729) para su nivel 1 (FERNANDEZ et alii, 1991).

Tabla 1. Dataciones de los niveles Chatelperronienses de los yacimientos españoles

\begin{tabular}{|c|c|c|c|c|}
\hline Yacimiento & Laboratorio & Nivel & Fecha & Desviación \\
\hline \multirow[t]{2}{*}{ Morín } & SI-951 & 10 & 27.776 & \pm 951 \\
\hline & SI-951-A & 10 & 35.873 & \pm 6.580 \\
\hline \multirow[t]{3}{*}{ Labeko Koba } & Ua-3034 & IX base & 26.575 & \pm 505 \\
\hline & Ua-3325 & IX centro & 29.750 & \pm 740 \\
\hline & Ua-3324 & IX base & 34.215 & \pm 1.265 \\
\hline Cova Da Valiña & GrN 17729 & 1 & 34.800 & $+1.900 /-1.500$ \\
\hline
\end{tabular}

Esta industria es la base del Paleolítico Superior y, según H. Delporte, se caracteriza por: 
- La presencia de la hoja de Chatelperron.

- La presencia de buriles sobre truncadura.

- La aparición clara de elementos del Paleolítico Superior.

- $Y$, finalmente, por la ausencia o pobreza de industria ósea típica. (Delporte, H., 1955).

Este período cultural presenta una industria en la que perviven elementos musterienses (raederas, puntas, cuchillos de dorso) y truncaturas, junto a la que encontramos la industria de hojas y un aumento en el número de raspadores y buriles. El elemento que caracteriza este período es la punta de Chatelperron que tiene una clara filiación con los cuchillos de dorso musterienses.

La distribución geográfica de esta industria se corresponde con la del Musteriense de Tradición Achelense, extendiéndose desde el Sudoeste de Francia, los Pirineos y penetrando en la Península Ibérica hasta Asturias.

Los restos humanos con los que se vincula esta industria pertenecen a neandertales que habrian realizado esta industria como un intento de adaptación a las industrias de hojas del Paleolítico superior. Destaca el enterramiento de Saint Cesaire descubierto en 1979, en el que restos materiales chatelperronienses aparecen vinculados con un individuo neandertal. Esto, junto con otros datos, llevó a que muchos autores atribuyeran esta industria a este grupo humano, siendo esta generalización excesiva ya que la información que se posee es parcial (Cabrera Valdés, V., 1996b).

En cuanto a España, los yacimientos se sitúan en la cornisa cantábrica. Aunque estos son escasos, se produce en ellos una continuidad estratigráfica entre el Paleolítico Medio y el Superior. Hay que destacar que este período sólo aparece constatado en el nivel 10 de Cueva Morín, en el nivel VIII de la cueva de EI Pendo y parece que también se detecta en la Cova Da Valiña (Lugo). La transición en esta zona proviene de niveles Musterienses de Denticulados, presentando los niveles del Perigordiense Inferior, no estadios iniciales sino algo ya evolucionados (Bernaldo de Quiros, F., 1981).

En cuanto a la tipología de las piezas, hay que decir que el Indice de Raspador es superior al Indice de Buril. Los útiles típicos del Perigordiense Inferior son las puntas de Chatelperron, que son más numerosas en Morín que en El Pendo. Tipológicamente éstas presentan un tipo evolucionado más cercano a las puntas de Les Cottes; a esto hay que añadir 
la presencia de piezas con retoque abrupto, hojas de borde abatido y troncadura.

\section{YACIMIENTOS DE PERIGORDIENSE INFERIOR EN ESPAÑA}

A continuación describimos los cinco yacimientos en los que se detecta esta fase cultural. Hay dos yacimientos en Cantabria, la cueva de El Pendo y Cueva Morín, y un yacimiento en Lugo, Cova Da Valiña, además de otros dos situados en Guipúzcoa.

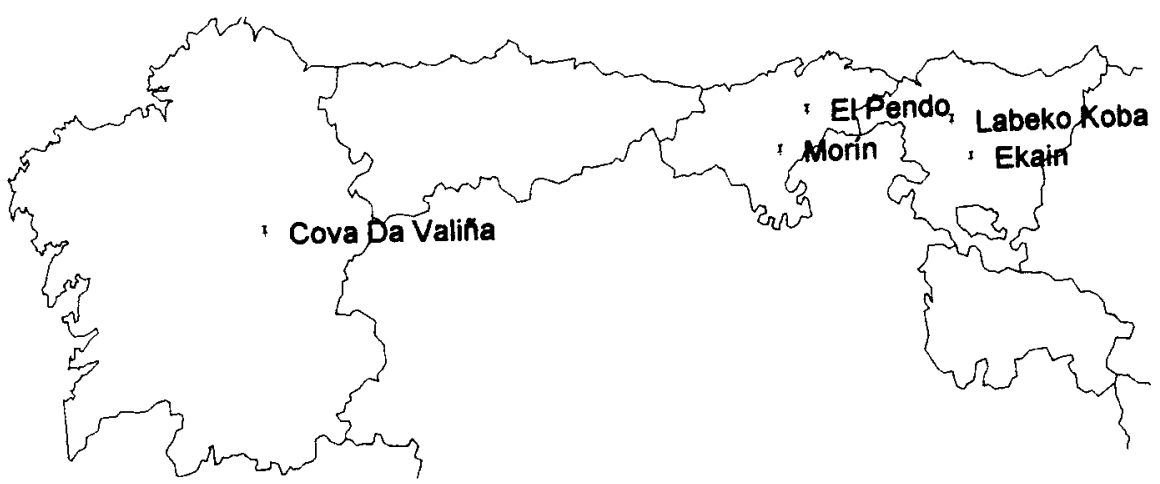

Figura 1. Yacimientos del Perigordiense Inferior.

\section{Cueva Morín}

El yacimiento fue descubierto en 1910 por $\mathrm{H}$. Obermaier y $\mathrm{P}$. Wernert, siendo reconocido por J. L. Ezquerra en 1911, que comunicó su existencia a J. Carballo. En 1912 se realiza el primer sondeo en la cueva, por J. Carballo y W. Beatty, que mostró un yacimiento compuesto de tres niveles.

Tras unos años en los que se siguen realizando sondeos, en $1917 \mathrm{~J}$. Carballo comienza las campañas de excavación, que durarán tres años. EI resultado de estas excavaciones se publica en 1923 por la Junta Superior de Excavaciones y Antigüedades. En la excavación de 1917 se realizó una trinchera que penetraba desde la entrada de la cueva en busca de su eje central. El corte realizado permitía ver todos los niveles del Paleolítico Superior y alguno del Paleolítico Medio. En la primera estratigrafía presentada por J. Carballo se aprecia la falta del Solutrense, mientras que el paso del Musteriense al Auriñaciense no se produce de manera brusca, 
aunque a veces aparece entre ambos una débil capa estéril (González Echegaray, J. 1971). En campañas sucesivas la trinchera fue ampliada para los niveles de Paleolítico Superior.

A partir de 1921 el yacimiento deja de ser visitado y no se vuelven a proseguir los trabajos de investigación en el mismo hasta cuarenta años después. En 1955 es cuando J. González Echegaray muestra interés por la estratigrafía de dicho yacimiento lo que le lleva a realizar una visita a la cueva acompañado por J. Carballo, gracias a la cual pudo ver que aún quedaba una parte del yacimiento por explorar.

Más tarde, en 1962, L. G. Freeman, que realizaba un estudio sobre el musteriense español, mostró deseos de conocer Cueva Morín, por lo que se organizó una visita a dicho yacimiento. El citado investigador se interesó a su vez por la estratigrafia de la cueva y le fue concedido un permiso para llevar a cabo un sondeo que dio unos resultados positivos y mostró que aún quedaba yacimiento para proseguir las excavaciones. Por ello en 1966 L. G. Freeman y J. González Echegaray deciden comenzar una campaña en la que se excava parte del testigo que los antiguos investigadores dejaron sobre la pared derecha de la cueva, a fin de constatar la estratigrafía (González Echegaray, J., 1971). Esta primera campaña sería seguida por otras dos, llevadas a cabo en 1968 y en 1969.

La estratigrafía del yacimiento se compone de 22 niveles que comprenden desde el Aziliense hasta el Musteriense de Tradición Achelense. De estos 22 niveles a nosotros nos interesa el nivel 10, que consiste en un estrato de 2 a $5 \mathrm{~cm}$ de espesor, compuesto por una arcilla de color negro oscuro y que se adscribe al Chatelperroniense. Este nivel se superpone a un nivel de $8-18 \mathrm{~cm}$ de espesor, que contiene una industria Musteriense de Denticulados.

Pero antes de plantear la existencia del Chatelperroniense como etapa transicional estaba el problema del llamado Auriñaco-Musteriense (González Echegaray, J. y Freeman, L.G., 1971), planteamiento que en su día fue estudiado y posteriormente refutado por J. González Echegaray y L. G. Freeman. Esta fase se consideró durante un tiempo como la antecesora del Auriñaciense y por lo tanto fue considerada como la etapa de transición entre las industrias del Paleolítico Medio y el Superior. Los yacimientos que sivieron para defender la existencia de esta etapa transicional fueron: el nivel "b" de $\mathrm{H}$. Obermaier en la Cueva del Conde, el nivel denominado como Auriñaciense Antiguo en Cueva Morín, el nivel A de Cova Negra, el nivel 9 del Otero y, finalmente el yacimiento de la Cueva del Cudón. Tras la revisión realizada por los mencionados autores, motivada por sus descubrimientos en Cueva Morín, llegaron a la conclusión de que no se puede justificar la existencia de este 


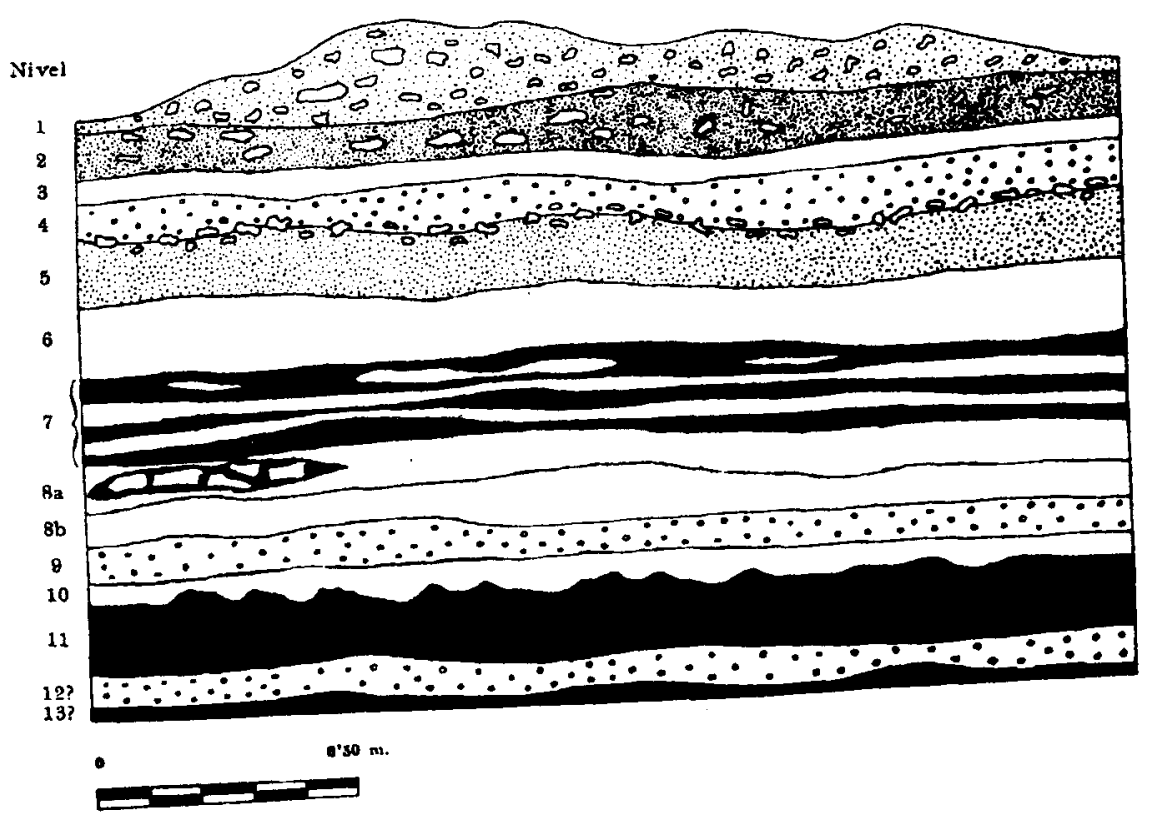

Figura 2. Estratigrafía de Cueva Morín (Según J. González Echegaray, 1971).

nivel de transición, siendo por consiguiente, el único nivel de transición entre el Paleolítico Medio y el Paleolítico Superior: el Chatelperroniense.

Este nivel es el primero del Paleolítico Superior en el yacimiento y presenta un total de $\mathbf{5 2 0}$ piezas clasificables. Son frecuentes los raspadores, presentando un Indice de Raspador de $13,6 \%$, destacando el raspador sobre lasca aunque no faltan otros tipos. Los buriles son muy abundantes, con un indice de $12,1 \%$, destacando los buriles diedros. Aunque raspadores y buriles son atípicos, presentan suficientes formas típicas y bien acabadas, propias del Paleolítico Superior. En cuanto a las puntas de Chatelperron, se encuentran representadas por 10 ejemplares, siendo cuatro de ellas típicas y las restantes atípicas. Es destacable la abundante presencia de piezas de carácter musteriense, que van a indicar su perduración, como son escotaduras, denticulados, también abundan las raederas, apareciendo algunas de tipo Chatelperroniense, similares a las descritas por A. Leroi-Gourhan en el yacimiento de Arcy-sur-Cure (LeroiGourhan, A., 1969) y que denomina pequeñas raederas chatelperronienses. Todo esto complementa el carácter Perigordiense de esta industria (González Echegaray, J. y Freeman, L.G., 1971). Además de todas estas 
piezas, no hay que olvidar la aparición de hojitas, que están representadas por una hojita denticulada y por una hojita Dufour.

Hay que destacar que este nivel no se superpone, como ocurre en las secuencias francesas, a un Musteriense de Tradición Achelense B, sino que se superpone a un Musteriense de Denticulados.

Aparte de los datos tipológicos, no olvidemos tampoco la estadística realizada por los autores respecto a este nivel en la que el Indice para el Grupo Auriñaciense es de un 5,9\% siendo ligeramente inferior al del Grupo Perigordiense con un $6,7 \%$. Este nivel se puede unir tipológicamente al Chatelperroniense por la presencia de las puntas de Chatelperron, la ausencia de elementos auriñacienses, y por la presencia de útiles musterienses (Bernaldo de Quiros, F.,1982).

\section{La cueva de El Pendo}

La cueva de El Pendo está situada en las cercanias del pueblo de Escobedo de Camargo (Cantabria). En 1878 es visitada por Sanz de Sautuola, y en 1880 se llevan a cabo las primeras excavaciones, realizadas por M. Sanz de Sautuola y J. Vilanova y Piera.

En 1910 J. Carballo realiza sondeos arqueológicos, que serán continuados en 1914 por R. Shallcras En esta época también se lleva a cabo una prospección a cargo de O. Cendrero, Gómez Llueca y C. Pérez Bustamante, produciéndose el descubrimiento del «bastón de mando». En 1924 J. Carballo consigue iniciar las excavaciones depositándose los materiales encontrados en el Museo Arqueológico Nacional. Las excavaciones continuarán durante los años siguientes descubriéndose en 1926 un nuevo "bastón de mando" que aparece decorado con grabados.

En 1930 se produce una colaboración hispano-norteamericana que se traducirá en una breve campaña de excavaciones. Esta vez el trabajo se efectúa junto a la pared este, apareciendo un estrato fértil atribuido a un Magdaleniense final. Las excavaciones prosiguen durante unos años y posteriormente se produce un parón en ellas.

El trabajo en el yacimiento se retoma en 1953. La zona escogida para llevar a cabo los nuevos trabajos es el terreno situado más al norte de las excavaciones realizadas por M. Sanz de Sautuola. En 1954 se produce la última intervención en el lugar.

Posteriormente se realizaría una revisión de estas dos últimas campañas a cargo de J. González Echegaray y otros expertos. 

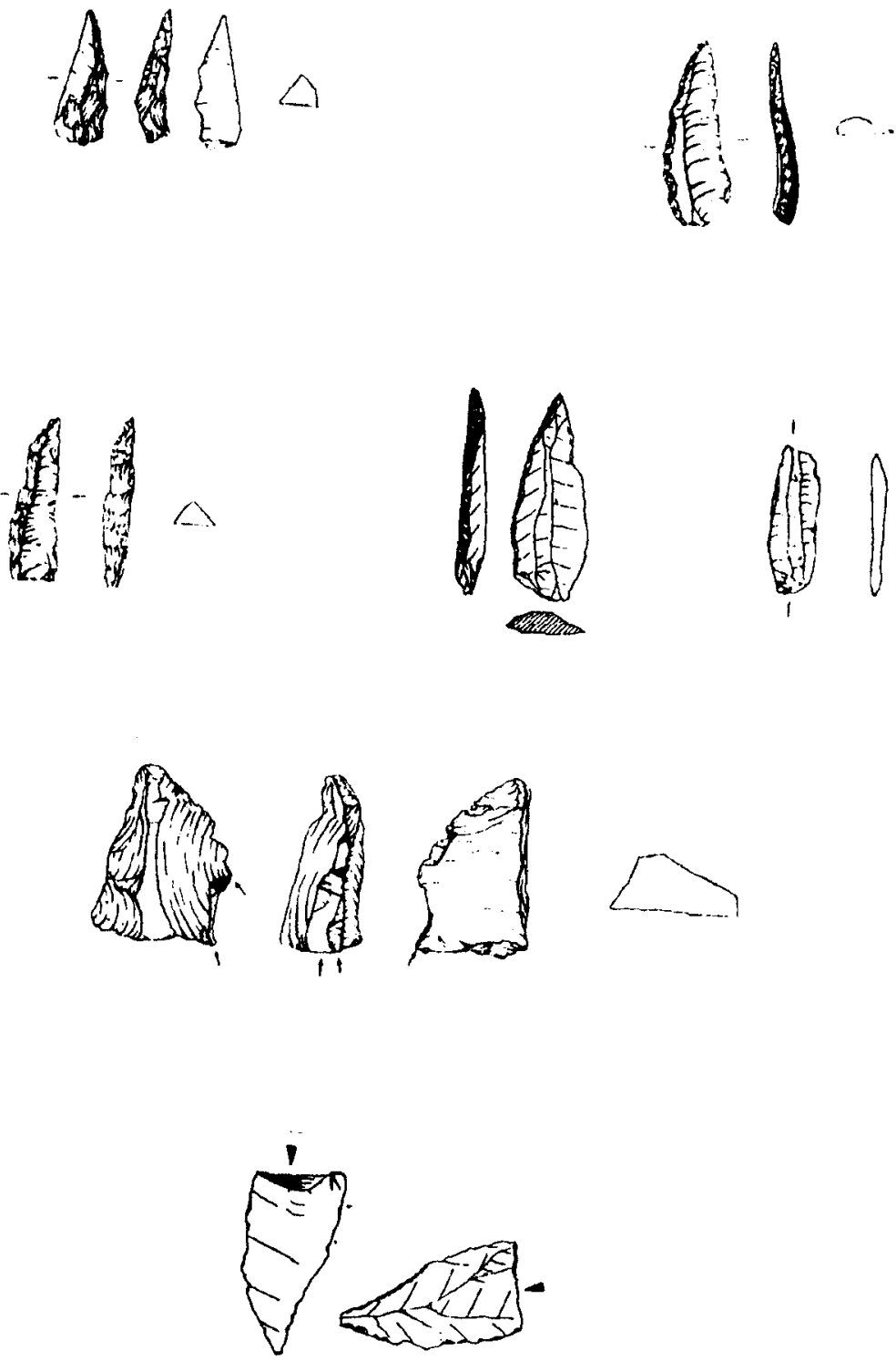

Figura 3. Industria Chatelperroniense del nivel 10 de Cueva Morín. (Según J. González Echegaray y L. G. Freeman, 1971). 
Respecto a la estratigrafía, ésta se compone de 18 niveles que incluyen industrias del Paleolítico Medio al Paleolítico Superior. Aquí prestaremos atención al nivel VIII que es el que abarca el período de estudio en el presente artículo. Destacaremos el nivel VIII, que es el que comprende la industria Chatelperroniense; este es un nivel de unos $12 \mathrm{~cm}$ de espesor, compuesto por un limo muy negro, fragmentos de ocre y muchos huesos, que va a contener 79 piezas.

Lo que se puede apreciar a simple vista es que el nivel VIII b se superpone a un nivel estéril (VIII c) que a su vez se encuentra sobre un nivel de Musteriense de Denticulados (VIII d); también se aprecia que los niveles Auriñacienses, Perigordienses y Gravetienses se encuentran interestratificados, lo que lleva a pensar a los investigadores en la evolución in situ del Paleolítico Peninsular descartando la posibilidad de que se haya producido una invasión que trajera estas industrias a la Península.

Este nivel está representado de forma fragmentaria, ya que como hemos dicho más arriba, sólo consta de 79 piezas. En él podemos apreciar cómo se produce una disminución de los caracteres auriñacienses, quedando reducido el Indice del Grupo Auriñaciense al 6,3\%, siendo por lo tanto de idéntico valor que el Indice del Grupo Perigordiense.

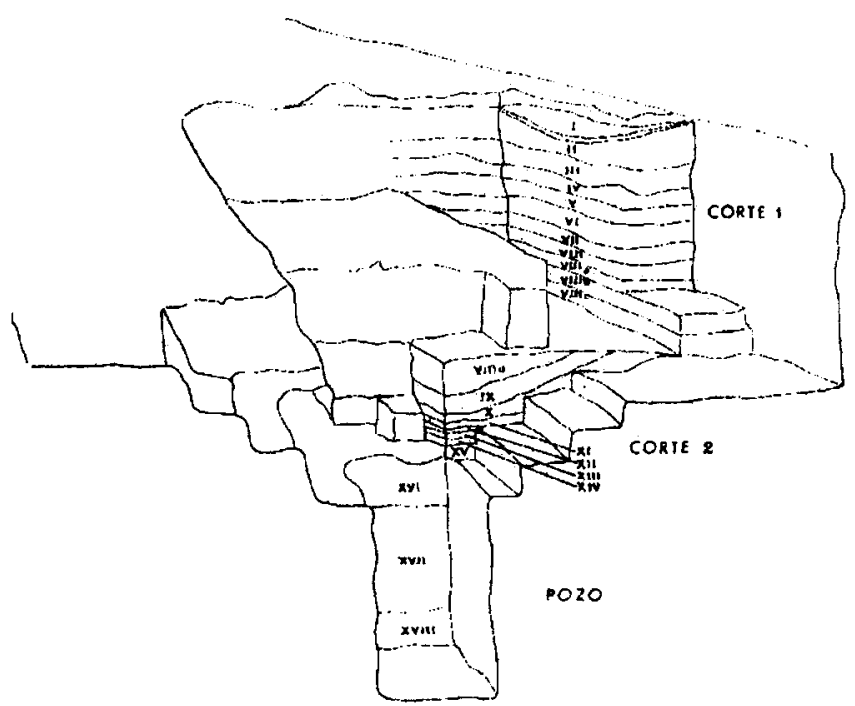

Figura 4. Alzada del área de excavación de El Pendo. (Según García Lorenzo, 1953). 

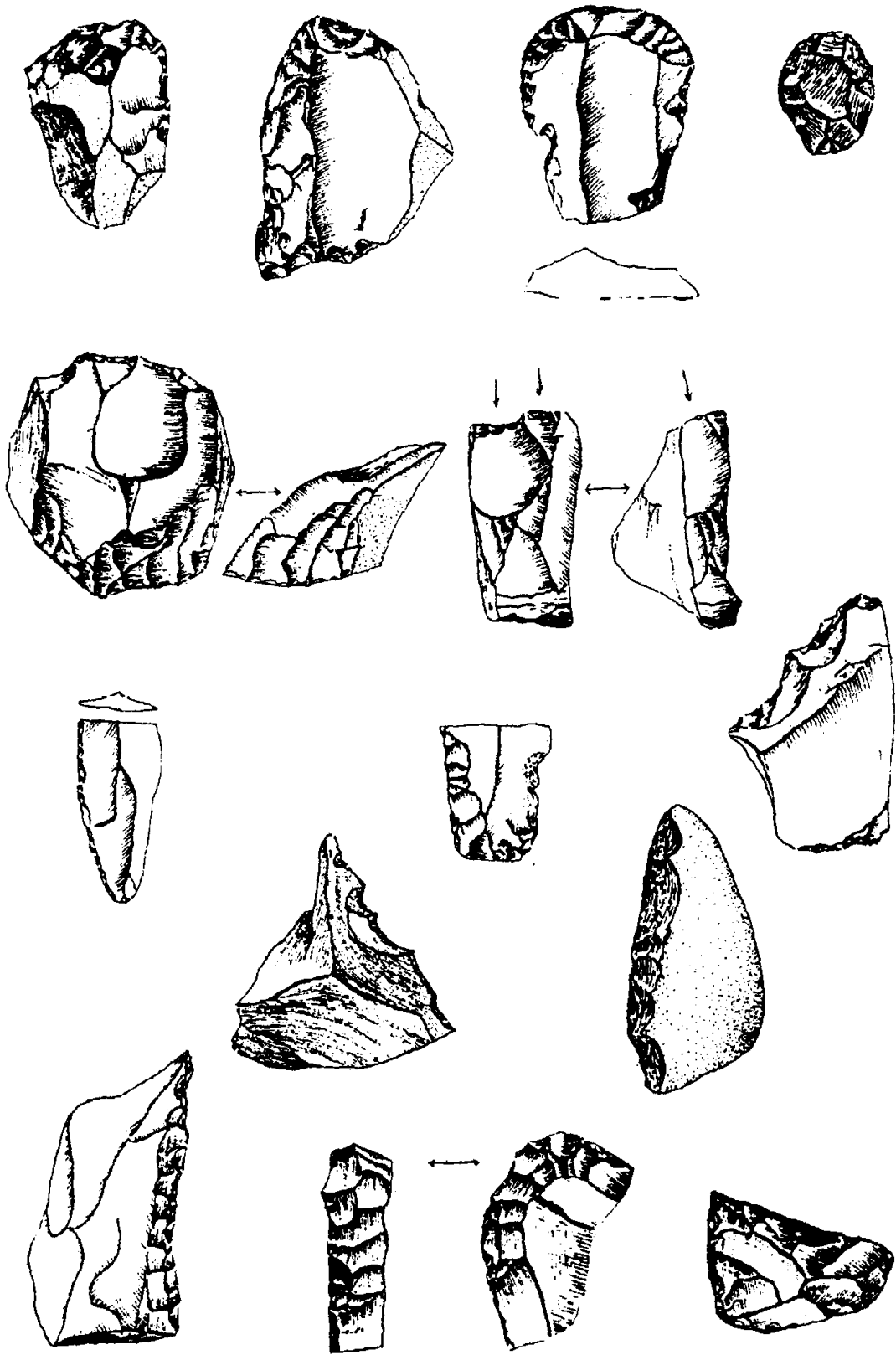

Figura 5. Materiales del nivel VIII de El Pendo. (Según F. Bernaldo de Quiros, 1981). 
La industria que aparece consiste en raspadores, siendo el más abundante el raspador sobre lasca, presentando un índice 16,5\%; también están presentes los buriles, aunque son escasos, presentando un Indice de Buril de 10,1\% siendo frecuente el tipo sobre rotura, aunque no faltando otros tipos; en este nivel se encontraron tres puntas de Chatelperron, siendo una de ellas típica.

Aquí, al igual que ocurría en Morín, las piezas de carácter musteriense son también abundantes, apareciendo un elevado número de raederas y de piezas denticuladas.

Este nivel se incluye en el Chatelperroniense no sólo por la aparición de las puntas de Chatelperron sino también por la presencia de un elevado número de útiles de carácter musteriense, en concreto las raederas. A esto hay que añadir la escasez de buriles y la importancia que adquieren los raspadores sobre lasca.

\section{Labeko Koba}

Este yacimiento se encuentra situado en Guipúzcoa. Se tienen conocimientos de su existencia en 1972, cuando se recogieron restos óseos en una galería de la cueva. Más tarde se llevo a cabo un sondeo en dicho lugar lo que permitió comprobar que los materiales formaban parte de la zona inferior de una capa de sedimentos que bloqueaba la antigua entrada de la cueva. Desde 1982 el hallazgo aparece registrado en la Carta Arqueológica de Guipúzcoa, dándose a conocer en este momento una probable cronología Auriñaco-Perigordiense. A parir de 1987 se inician las labores de excavación del yacimiento. Estos trabajos duraran desde 1987 hasta 1989, año en que la cueva fue destruida por las obras de la Variante de Arrasate.

Su secuencia estratigráfica consta de diez niveles, interesándonos a nosotros el nivel $x$ que se superpone al nivel $x$ que es la base del deposito y no contiene ningún vestigio arqueológico.

El nivel IX tiene más de un metro de espesor y en él aparecen restos de talla y lascas aunque la mayoria del material encontrado se corresponde con restos de fauna. En su base aparecieron tres puntas de Chatelperron, dos raederas y algún otro útil aislado (Arrizabalaga Valbuena, A., 1993). Esto lleva a datarlo como un nivel Chatelperroniense.

\section{La cueva de Ekain}

Esta cueva se encuentra situada en Guipúzcoa, siendo excavada entre 1973 y 1975 por J. Altuna. 
Su secuencia estratigráfica consta de doce niveles, siendo el nivel $X$ el que, dentro de su pobreza, aporta una laminilla de dorso y una punta de Chatelperron atípica (Altuna J. Et alii, 1984 y Esparza San Juan, 1993).

\section{Cova Da Valiña}

Este yacimiento no se encuentra situado, como los anteriores, en la Cornisa Cantábrica, sino que se localiza en Castroverde (Lugo).

Las primeras noticias que se tienen sobre la posible existencia de un yacimiento arqueológico en esta cueva datan de 1965, cuando Vázquez Seijas da a conocer el hallazgo de restos óseos en las proximidades. En 1971 se vuelve a mencionar la presencia de material óseo procedente de dicha cueva. A pesar de todo esto, y de su mención en otras publicaciones, no es hasta 1987 cuando se piensa en la existencia de un posible yacimiento del Paleolítico. En este año, César Llana y $\mathbf{M}^{\mathrm{a}}$ José Soto llevan a cabo la primera prospección en la Cova Da Valiña, que confirmará la presencia, al menos, de dos niveles arqueológicos en posición primaria (Llana, C. y Soto, M. J., 1991).

En cuanto a la secuencia estratigráfica, ésta viene dada por tres puntos diferentes, que son: el cuadro 12-D, el 30-G que proporciona la secuencia completa de la parte sur del yacimiento y, finalmente, el área correspondiente a la zona afectada por el expolio. Por desgracia, la destrucción de parte del yacimiento impide vincular la parte conservada en la zona norte con la de la sur (Llana, C. y Soto, M.J., 1991).

El cuadro 12-D/Este comprende cuatro niveles, correspondiendo el nivel 4 al nivel arqueológico 1 . Este nivel fértil tiene unos $68-85 \mathrm{~cm}$ de espesor, consistiendo en una alternancia de capas de material muy plástico, de color marrón amarillento y de textura limosa a limo-arcillosa, con capas endurecidas por la precipitación de óxidos de hierro. En la base aparece una línea de piedras calizas alterada.

La colección de piezas hallada en el nivel 1 del yacimiento esta formada por un total de 130 piezas de las que 60 son útiles. Hay un predominio del soporte lascar $(56,66 \%)$ frente al laminar $(15 \%)$.

La industria de la cueva presenta un Indice de Raspador $(11,66 \%)$ inferior al Indice de Buril $(21,66 \%)$. Los raspadores se encuentran caracterizados por la mala calidad de su factura. Hay que destacar la poca importancia que van a tener los raspadores auriñacienses. 


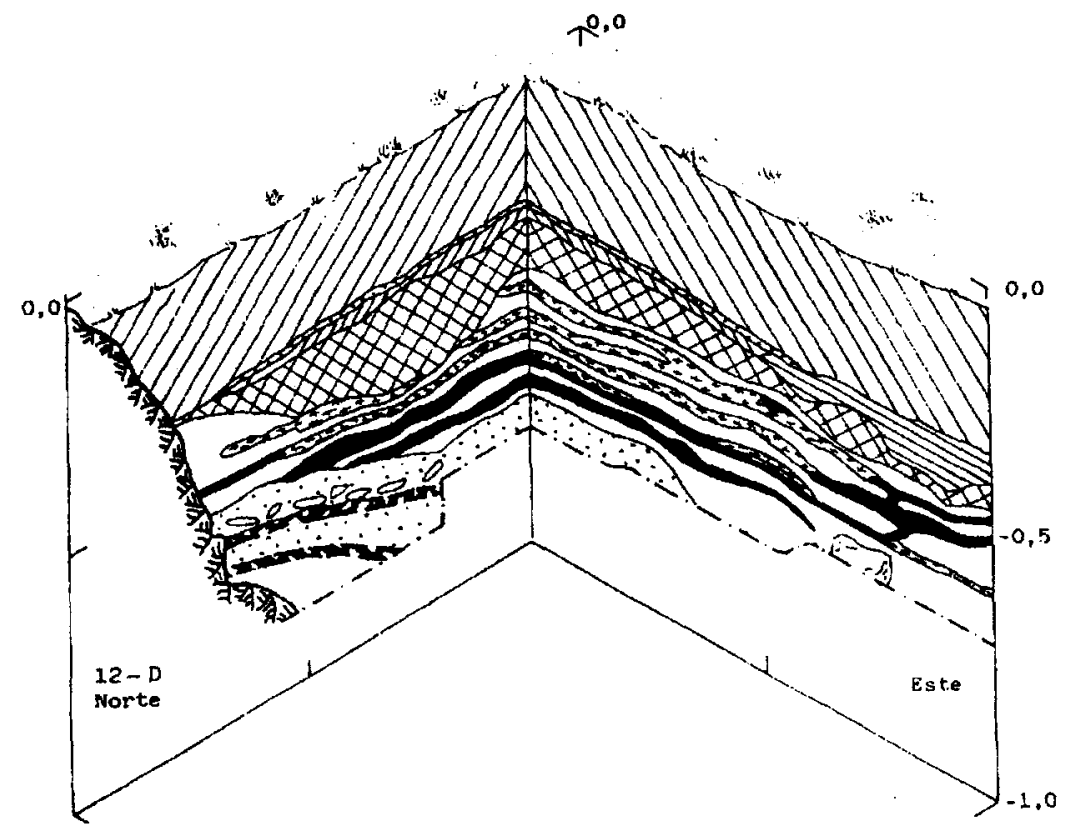

Figura 6. Corte estratigráfico de la Cova Da Valiña. (Según X. Lomba, 1991).

En cuanto a los buriles, como hemos dicho más arriba, presentan un índice superior al de los raspadores, estando mucho mejor representados que estos, predominando los diedros.

Aparte de estos dos conjuntos, también tenemos cuchillos de dorso del tipo Abrí Audí que corresponden a lascas de forma triangular, que presentan un frente semicircular delimitado por un retoque abrupto más o menos circular, relacionándolos R. Villar Quintero con los tipos de cuchillos de dorso sobre lascas largas pertenecientes a los niveles iniciales del Paleolítico Superior (Villar Quintero, R., 1991).

Hay también piezas de carácter musteriense como son los denticulados, que presentan un porcentaje elevado; raederas, estando bien caracterizadas las realizadas sobre lasca. Una de estas raederas parece que podria estar relacionada con las descritas por A. Leroi-Gourhan y que ya hemos nombrado anteriormente (Villar Quintero, R., 1991).

Entre todas las piezas se encuentra un fragmento correspondiente al extremo distal de una lámina apuntada que presenta un fino dorso realizado con un retoque abrupto poco profundo, siendo identificada por los 

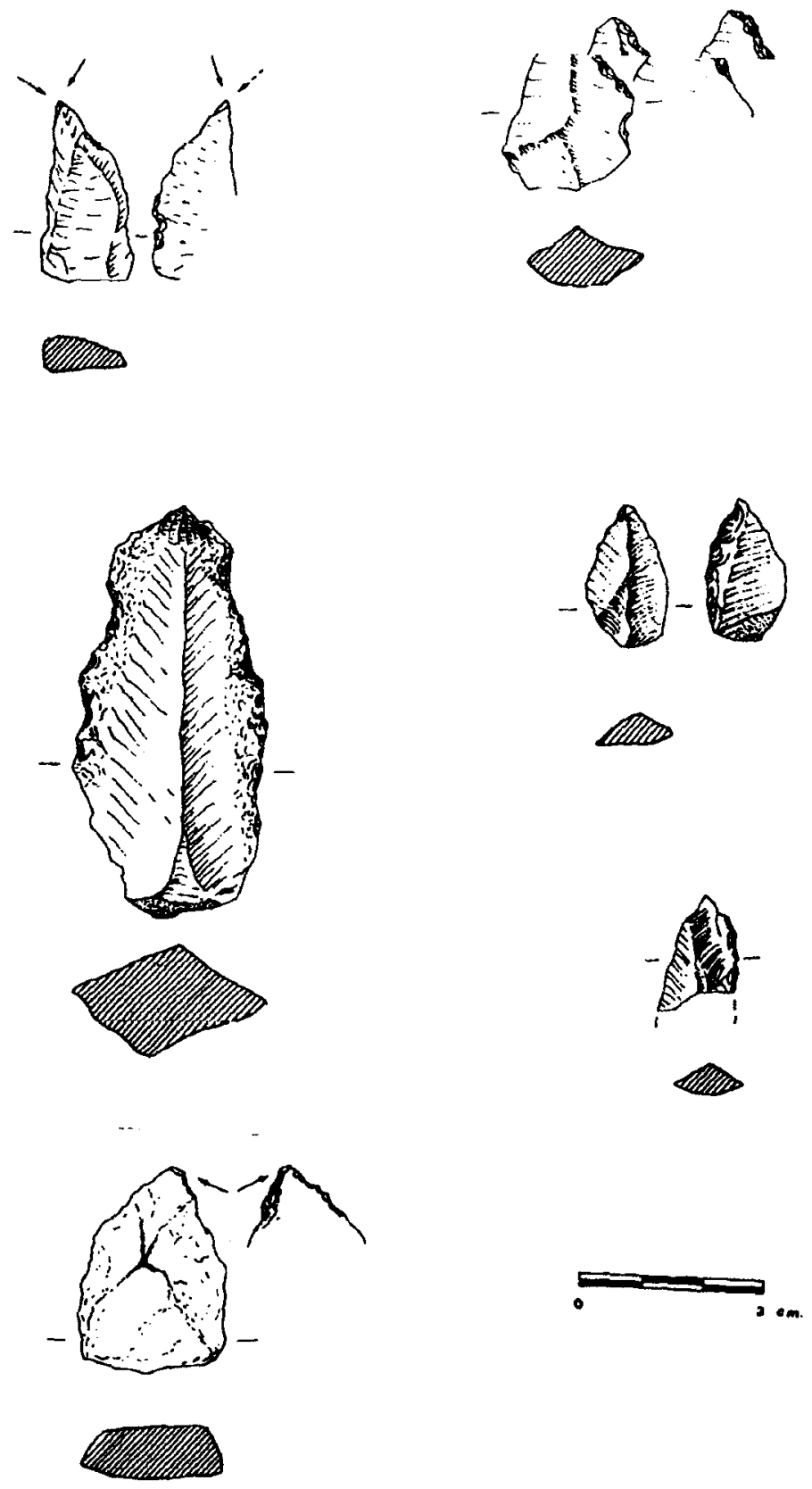

Figura 7. Industria de la Cova Da Valiña. (Segün X. Lomba, 1991). 
investigadores de dicho yacimiento como fragmento perteneciente a una punta de Chatelperron. Esta identificación la realizan haciendo una reconstrucción que constata un dorso con cierto grado de curvatura, que es lo que les lleva a relacionar este fragmento con el tipo Chatelperron (Villar Quintero, R., 1991).

Para finalizar, decir que el Indice del Grupo Auriñaciense (5\%) es muy inferior al del Grupo Perigordiense (18,33\%). Esto es debido a que en el conjunto de la Valiña aparece una mayor cantidad de útiles que se relacionan con el complejo Perigordiense. Debido a esto y a las características tipológicas de las piezas, los investigadores de este yacimiento lo relacionan con los inicios del Paleolítico Superior y en concreto con el Chatelperroniense.

\section{CONCLUSIONES}

Como hemos visto, los escasos yacimientos que presenta este período transicional se encuentran ubicados principalmente en la zona cantábrica. Este período aparece caracterizado por un Indice de Raspador superior al de Buril, por la pervivencia de elementos de tradición musteriense $y$, al contrario de lo que ocurre en las secuencias francesas, donde dicha etapa parece derivar de un Musteriense de Tradición Achelense Tipo B; en los yacimientos cantábricos se superpone a un Musteriense de Denticulados.

Hemos visto los yacimientos en los que podemos encontrar esta industria; sobre esto hay que decir que tanto Morín como El Pendo no presentan ninguna duda en cuanto a la adscripción de sus niveles a esta industria. En cuanto al yacimiento de Cova Da Valiña, pensamos que puede ser prematuro adscribirlo a esta etapa cultural, en tanto no tengamos más datos. Si bien es cierto que algunas de las características que ofrece su industria son coincidentes con lo encontrado en los otros yacimientos, no ha aparecido ningún fósil director de este período, como es el cuchillo de Chatelperron, excepto el pequeño fragmento que los excavadores de dicho yacimiento identifican como tal.

Este yacimiento no se adapta a algunos de los rasgos de carácter general que presentan el resto de enclaves con esta industria. En Cova Da Valiña el Indice de Raspador es inferior al de Buril, mientras que en Morín y El Pendo esto ocurre al contrario; los niveles chatelperronienses no sabemos si se superponen a algún nivel como ocurre en estos dos últimos yacimientos.

Es arriesgado adscribir este nivel de ocupación al Chatelperroniense, basándonos en la pobreza de datos de que disponemos a lo que hay que 
añadir la desaparición de parte del yacimiento debido a la acción de los furtivos. En este enclave arqueológico tampoco podemos utilizar la presencia de fósiles directores, tal como dicen los investigadores, puesto que la única pieza que tenemos es dudosa ya que contamos sólo con el ya citado fragmento identificado como perteneciente a una hoja de Chatelperron, identificación, en nuestra opinión, un poco arriesgada.

Este yacimiento gallego sólo se podría incluir en este período debido a la fecha que presenta (GrN 17729, $34.800+1.900 /-1.500$ ), ya que ésta entra dentro de las que comprende este período y estaría comprendida entre las fechas más antiguas para este período conseguidas en España. Pero este no es el único factor que hay que tener en cuenta para adscribir un nivel o un yacimiento a un período cultural determinado; a esto hay que sumarle los restos materiales encontrados, que en este caso concreto son pocos y plantean dudas respecto a su adscripción.

A pesar de todo esto, habrá que seguir de cerca la evolución de los trabajos de investigación que se realicen sobre el Paleolítico gallego y no perder de vista yacimientos como éste, puesto que nos pueden aportar datos que relacionen tanto la zona cantábrica como la gallega. Esperamos que pronto nos lleguen más datos sobre este yacimiento que corroboren definitivamente su industria a los comienzos del Paleolítico Superior, y en concreto al Chatelperroniense, pero hasta que esto ocurra habrá que ser cautos y de momento seguir pensando que sólo tenemos dos yacimientos donde con toda seguridad se dá esta etapa de transición.

\section{BIBLIOGRAFIA}

AltunA, J. et alii (1984): El yacimiento prehistórico de la cueva de Ekain (Deba, Guipúzcoa). Eusko lkaskuntza, Sociedad de Estudios Vascos, San sebastián.

Arrizabalaga Valbuena, A. (1993): «El yacimiento arqueológico de Labeko Koba (ArrasateMondragón-Guipúzcoa). Aportación al Paleolítico Superior inicial vasco" en El origen del hombre moderno en el Suroeste de Europa, pp. 195-208. UNED, Madrid.

arrizabalaga Valbuena, A. (1995): La industria lítica del Paleolítico Superior Inicial en el oriente cantábrico. Tesis doctoral. Universidad del Pais Vasco.

Bernaldo DE Quirós GuIDOTI, F. (1981): «Las industrias del Paleolítico Superior Inicial en la Región Cantábrica española" en Trabajos de Prehistoria, Vol. 38, C.S.I.C. Madrid.

Bernaldo de Quirós GuIdotTI, F. (1982): Los inicios del Paleolítico Superior Cantábrico, C.I.M.A, Madrid.

Bernaldo de QuiRós Guidottı, F. (coor.) (1994): «Las industrias del Paleolítico Superior Inicial Cantábrico" en El cuadro geocronológico del Paleolítico Superior Inicial. Museo y centro de investigación de Altamira, monografia 13. Madrid.

BORDES, F. (1968): "La question périgordienne" en La Préhistoire: probièmes et tendances, págs. 59-70. París.

BORDES, F. (1972): «Du Paléolithique moyen au Paléolithique supérieur, continuité ou discontinuité?" en Origine de l'homme moderne, págs. 211-218. París.

Cabrera Valoés, V. (1996a): "Del Musteriense al Paleolitico Superior" en Gallaecia, 14-15, págs. 123-130. Universidad de Santiago de Compostela. 
Cabrera Valdés, V. (1996b): “El Paleolítico Medio en Europa» en Prehistoria I, págs. 317341. UNED:

CABRERA VALdÉs, V. et alii (1996): "La transition Paléolithique moyen-Paléolithique supérieur à El Castillo (Cantabrie): nouvelles datations par le carbone 14" en C.R. Académie des Sciences, t. 322, série II a, págs. 1.093-1.098, París.

Delibrias, G. y EVIN, J. (1974): “Sommaire des datations 14C concernant la préhistoire en France: I. Dates parues de 1955 à 1974" en Bulletin de la Société Préhistorique Française, vol 71, págs. 149-156.

Delibrias, G. y EvIN, J. (1980): "Sommaire des datations 14C concernant la préhistoire en France: II. Dates parues de 1974 à 1978" en Bulletin de la Société Préhistorique Française, vol 77 , págs. $215-223$

DeLPORTE, H. (1954): «Le Perigordien» en Bulletin de la Société Préhistorique Française, vol LI, págs. 44-48.

DELPORTE, H. (1955): "L'industrie de Châtelperron et son extension géographique" en Congrés Préhistorique de France, vol. 14, págs. 233-250.

DELPORTE, H. (1956): «Les facies castelperroniens et leur repartition géographique» en Crónica del IV Congreso Internacional de Ciencias Prehistóricas y Protohistóricas (Madrid, 1954), págs. 225-234, Zaragoza 1956.

Esparza SAN JUAN, X. (1993): “Los complejos Preauriñaciense: El Castelperroniense y el Protoauriñaciense, en el Pirineo occidental" en El origen del hombre moderno en el Suroeste de Europa, pp. 209-218. U.N.E.D., Madrid.

FREMAN, L.G. (1993): “La transición en Cantabria. La importancia de Cueva Morín y sus vecinos en el debate actual» en El origen del hombre moderno en el Suroeste de Europa, págs. 171-193. U.N.E.D., Madrid.

Gonzalez Echegaray, J. et alii (1971): Cueva Morín. Excavaciones 1966-1968. Santander.

Gonzalez Echegaray, J. et alii (1973): Cueva Morín. Excavaciones 1969. Santander.

GonzAlez Echegaray, J. et alii (1980): El yacimiento de la cueva de "El Pendo" (Excavaciones 1953-1957), Bibliotheca Praehistorica Hispana, vol. XVII, Madrid.

HaRROLD, F.B. (1981): “New perspectives on the Chatelperronian» en Ampurias, t 43, págs. 1 51, Barcelona.

HEDGes et alii (1994): Ractiocarbonatates from the Oxford Ans Systen. Archaeometry data list 18. Archaeometry 4. 96 , pp. 337-374.

JORDÁ CERDÁ, F. (1952): "El problema del Chatelperroniense (Auriñaciense Inferior) en España" en Cónica del VI Congreso Arqueológico del Sudeste, Alcoy 1951-Cartagena 1952.

LAPLACE, G. (1962): "Recherches sur l'origine et l'èvolution des complexes leptolithiques" en Quaternaria, V, págs. 153-214.

Lerol-Gourhan, A. (1969): “Le petit racloir chatelperronien" en La Prèhistoire Moderne. Problemes et tendances. París.

LÉvÉQUE, F. (1997): “Le passage du Paléolithique Moyen au Paléolithique Supérieur: données stratigraphiques de quelques gisements sous-grotte du sud-ouest» en Quaternaire,8, (2-3), págs. $279-287$.

LlanA, C. y Soto, M.J. (dir.) (1991): Cova Da Valiña (Castroverde, Lugo). Un xacemento do Paleolítico Superior Inicial en Galicia. (Campañas de 1987 e 1988). Arqueoloxía/ Investigación 5. Xunta de Galicia.

Lucas Pellicer, M.R. (1985): "El Paleolítico. La etapa depredadora" en Historia General de España y América, t 1, págs. 3-162. Editorial Rialp. Madrid.

Moure RomanilLo, J.A. (1970): “Industrias auriñacienses y preaurinaacienses en la Región Cantábrica española" en Ampurias, t. 31-31, págs. 71-90. Barcelona.

Pradel, L. (1952): “Caractéristiques lithiques des différents niveaux périgordiens en France" en Bulletin de la Société Préhistorique Française, vol XLIX, págs. 531-543. 